\title{
Perceptions of Technological Change at Work through a Gender Lens
}

\section{Katrin Golsch, Marco Seegers}

\begin{abstract}
In Germany, like in many other countries, much of the research on technological changes and their consequences has been devoted to investigating the field of industrial production. A shortcoming of this research is that many female-dominated occupations are excluded per se from consideration. However, whether and to what extent men's and women's perceptions of technological changes in their workplace differ is an important subject of debate. This article addresses the following questions: To what extent are men and women experiencing changes in the technologies of their workplace? Are women less likely to experience such changes? Do men and women anticipate to differing degrees a threat to their future job security and the skills demanded of them? And do they expect technological changes in their workplace to impact their health or work performance demands? The analysis, based on data from the Socio-Economic Panel Study (SOEP, 2015-2017), compares men and women across gender-typical and gender-atypical occupations and identifies conditions that increase or decrease perceived risks of technological change at work. The results indicate that technological change is perceived as most threatening in female-dominated occupations, and especially by women.
\end{abstract}

Keywords: technological change, risk perception, gender

Golsch, Katrin, Seegers, Marco. 2020. Perceptions of Technological Change at Work through a Gender Lens. Gender a výzkum / Gender and Research 21 (2): 32-58, http://dx.doi.org/10.13060/gav.2020.013.

The technological transformation is changing the world of work and also has farreaching consequences in other areas of life (e.g. Hirschi 2018). The increasing use of computers and mobile devices is just one aspect of this process. The combination of automation and information technology is another aspect. Work processes are changing across all sectors and industries, but the extent and pace of change vary and this is often associated with high levels of individual uncertainty. It is thus important to study not just the pace and extent of technological change, but individuals' 
perceptions of risk as well. Both men and women may face particular challenges for work life, likely resulting in concerns about getting fired (Shoss 2017) and about not being able to keep up with the required technological skills or meet work performance demands (Hammermann, Stettes 2016), and may be concerned about health risks as well (Schulz-Dadaczynski, Junghanns, Lohmann-Haislah 2019). Germany is no exception to this fast-moving phenomenon and its multifaceted impacts on individual lives. Compared with other OECD member countries, previous research revealed that the majority of Germans see the consequences of technological change in general more as opportunities than as risks (OECD 2019).

With the focus on technological change at work, research has so far often ignored possible gender differences (Hauer 2016; Piasna, Drahokoupil 2017). Little is known about the extent to which women and men are affected in different ways by these processes, how they react to them, and what role is played by the occupational context they work in (e.g. Kutzner, Schnier 2017; Voss 2017). The last point could be particularly significant, given the persistence of occupational gender segregation in Germany (Busch-Heizmann 2015). This is already an important dimension of social inequality, because women's jobs are more often characterised by worse employment conditions, such as lower wages and limited career opportunities. Taking this inequality into account, it is important to gain deeper insight into the extent to which gender inequalities emerge or persist due to technological change (Ahlers et al. 2017). To date, the focus on technological innovations in the field of industrial production (Hirsch-Kreinsen, Ittermann, Niehaus 2018) and thus on male-dominated occupational fields in particular has been a key factor in the creation of the above-mentioned blind spot in this research field (Hauer 2016). The consequences of technological change in female-dominated sectors (e.g. in education, health, and nursing) are much less well-researched (Ahlers et al. 2018).

The goal of this study is to enhance understanding about the individual risk perception of technological change at work by systematically comparing men and women across gender-typical and gender-atypical occupations. An in-depth examination of men's and women's risk perceptions of technological change in the workplace is very significant because subjective concerns can have important consequences - for example, for an individual's health, work performance, turnover, and his or her willingness to participate in further training (e.g. Shoss 2017). In order to comprehensively investigate the consequences of technological change, a common understanding is needed that brings together subjective-individual perspectives and objective consequences.

The article is structured as follows. The next section presents the theoretical reasons for why it is important to study the risk perception of new technologies and why risk perception may be expected to differ by gender. To this end, theoretical approaches 


\section{NV STATI / ARTICLES}

on gender inequality in the work context will be linked to the broader literature on technological change at work. One research question driving the empirical part is: To what extent do men and women experience changes in the technologies of their workplace? Are women less likely to experience such changes? The next task is to study the subjective risk perceptions relating to this experience: To what extent do men and women anticipate changing skill demands, and do they expect to lose their job in the near future? Do men and women expect to differing degrees that technological changes in their workplace will impact their work performance demands or health? The three most recent waves of the SOEP (2015-2017) serve as a database for this analysis, as described in the method section. The results section presents the findings of our study, and the last section summarises the findings and suggests areas for future research.

\section{Theoretical considerations}

\section{Technological change at work: risks and opportunities}

The focus of the present article is not on risks with regard to technological change at work in general but on subjective risk perceptions. However, a question that needs to be answered beforehand is from a theoretical point of view: What risks and opportunities may arise from technological change for both genders?

First and foremost, technological change promotes the permanent restructuring of the labour market and thus also of occupational profiles and jobs. This requires a permanently high willingness to adapt from employees (Hasselmann, Schauerte, Schröder 2017). Taking a task-based approach, it is assumed that technological change will influence work tasks (Autor, Levy, Murnane 2003). On the one hand, human tasks can be substituted by the adoption of technical applications, which can lead to the automation of tasks. On the other hand, new tasks, work requirements, and conditions can be created that may have positive and negative effects on employees. Both are likely to change the occupational structure within industries and across sectors (Kruppe et al. 2019). From a micro-employee perspective, technological change is therefore defined as the introduction of new (digital) tools and technologies in the work context, which have a significant impact on the individuals who work with them.

The risk of substitution varies depending on a job's requirements (Arntz, Gregory, Zierahn 2016) and is expected to be lower for tasks that require a high degree of creativity, spontaneity, cooperation, or interaction (Hardy, Keister, Lewandowski 2016). While the average risk of substitution is high in the manufacturing sector and in construction, transportation, and retail, the average risk of being displaced 
seems lower in social and cultural service professions and in medical and nonmedical health professions (Kruppe et al. 2019). However, a high risk of substitution is not only observed in male-dominated occupations (e.g. in precision mechanics and toolmaking, metalworking, and the production of foodstuffs) but also in some female-dominated sectors (e.g. doctors' receptionists and assistants, retail sales occupations, housekeeping, consumer advice, and cleaning). Nevertheless, based on their task profiles, women-dominated occupations are less at risk of substitution than men-dominated occupations in all OECD member countries (except Japan) (Krieger-Boden, Sorgner 2018). Risks and opportunities associated with technological change also depend on task profiles, which differ between male- and female-dominated occupations (Seegers 2020). Compared to maledominated occupations, female-dominated occupations that are directly affected by technological substitution are often characterised by a higher share of interactive tasks and a lower share of autonomy and variety. A related issue is the extent to which the risks of technological change depend on skills. It is assumed that human skills must be adapted to the changing work requirements that result from the implementation of new technology. The attractiveness of advanced training is thus increasing for men and women in the wake of technology-induced changes in tasks (Berger, Frey 2016).

With regard to gender differences, prior studies paint a mixed picture. With few exceptions (e.g. ICT specialist skills), there is virtually no evidence of significant gender differences in skills that are required by jobs due to technological change, and women seem to profit from the creation of highly skilled jobs (OECD 2017). At the same time, other trends do point in the direction of women's greater vulnerability due to their position in the labour market, since women still hold a more restricted range of jobs and hierarchical positions than men, and technological change contributes to this segregation (Piasna, Drahokoupil 2017).

As a result of changing work tasks, work requirements also change (both the physical and psychological demands). The most direct negative effect is that the workload and the number of tasks to be performed simultaneously have often significantly increased, resulting in higher levels of work pressure (DGB Index Gute Arbeit 2016, 2017). But there are also positive effects as there is a more flexible framework for employees' decision-making (BMAS 2016). The opportunity to work outside of their normal workplace has increased for many women, especially among highly qualified women and female executives (Lott 2014). Flexible working-time arrangements are on the rise, too, and this facilitates the compatibility of work and family in some cases, especially among full-time employees. However, it also blurs boundaries between work and family life, with the potential to exacerbate stress-based work-family conflicts (Rump, Eilers 2017). Various tasks are also becoming less physically demanding, but 


\section{NV STATI / ARTICLES}

in many cases the increased work demands outweigh these gains on the physical side, and there is also often more psychological stress (BMAS 2016).

In an overall view of the results described so far, we know that technological change is a multifaceted process that is significantly changing work processes, and women's occupations are not exempt from this. This often creates an uncertain workplace setting, including various risks to which men and women may be exposed. In particular, this refers to the risk of getting fired and of not being able to keep up with the technological skills required for the job or meet work performance demands, as well as health-related risks. In the following analysis, the important point is that these risks are likely to be perceived differently across work settings and gender. This should not obscure the fact that technological change may also have facilitative effects. The individual's chances of profiting greatly - or at all - from technological change will depend on a set of personal, structural, and occupational characteristics.

\section{Subjective risk perception of technological change at work}

The discussion now turns to subjective risk perception. Our approach builds on ideas taken from Wachinger et al. (2013: 1049), who define risk perception as a 'process of collecting, selecting and interpreting signals about uncertain impacts of events, activities or technologies'. Various (perceived) risk characteristics can form the basis for this process (Slovic 2000; Slovic, Fischhoff, Lichtenstein 2000). What is special in the context of technological change is that the extent and pace of this change and its associated hazards are unknown and for many are not controllable. Risk perception of technological changes refers to men's and women's judgements about the likelihood of getting fired and not being able to keep up with the technological skills required for a job or meet work performance demands, as well as health risks. Theoretically, these risk perceptions are not only the result of men's and women's cognitive judgements, but also stem from their feelings, particularly if access to detailed information about risks is lacking (Loewenstein et al. 2001). In addition, according to the ideas of Slovic (2000) and Kahnemann, Slovic, Tversky (1982), individuals working in sectors and occupations that have already been exposed to technological change may evaluate the changes at their own workplace as particularly risky.

To date, too few empirical studies focus on the employees themselves and their perception of the risks attached to technological change in the work context. One finding from previous research on Germany is that few employees worry about losing their jobs due to technological change, especially if they are highly skilled employees, while many men and women report increased training needs (BMAS 2016). Evaluating the perceived workload, just under a half of employees say that their workload has increased as a consequence of technological change (especially due to the need to 
multi-task and be constantly available) (DGB Index Gute Arbeit 2016). The strain this involves and the associated fatigue and psychological problems increase with the educational level of employees (BMAS 2016).

The question, however, is whether technological change and its consequences for jobs are subjectively experienced and interpreted differently. According to Wachinger et al. (2013: 1049), risk perceptions 'may differ depending on the type of risk, the risk context, the personality of the individual, and the social context'. As described above, technological change can have an impact on men's and women's perception of four different types of risks: risk of losing one's job (Shoss 2017), concerns about skill requirements or work performance demands (Hammermann, Stettes 2016), as well as health-related risks (Schulz-Dadaczynski, Junghanns, Lohmann-Haislah 2019). Gender differences in risk perception may be due to a number of objective factors that characterise the risk context (such as differences in the form of job qualification requirements, work-related tasks, or working arrangements) and to subjective factors (such as risk preference and other personality traits, self-perception). From labour market research we already know that the importance of individual characteristics (e.g. gender, age, education) for inequalities among employees varies within and across occupations in diverse sectors (Autor, Handel 2013). As will be shown later, not only company structures and practices but also discrimination and stereotyping processes form the background for reflections on the unequal distribution of opportunities for individual groups of employees within a company. However, previous digitalisation research has not highlighted the consequences of these stereotyping and discrimination processes for the everyday work of women and men (Oliveira 2017).

To what extent these factors actually play a role in men's and women's risk perceptions, must in the light of the current state of research be seen as a question that still remains to be answered. Although relevant, there is scant theoretical and empirical knowledge about the extent to which men and women perceive technological change at work differently. In some studies on Germany, gender differences have been found, as women more often feel they are at the mercy of technology. Women have less say and decision-making power than men in the adoption and use of digital technology in companies (DGB Index Gute Arbeit 2017). Full-time female employees report higher levels of workload intensification, while men are more likely to report changes in work demands (DGB Index Gute Arbeit 2016, 2017). These studies do not systematically compare men and women across gender-typical and gender-atypical occupations, however. The following discussion outlines why we can expect gender differences in the perceived risks of technological change in the workplace. Our particular interest lies in bringing greater focus to the role of gender segregation in the labour market. 


\section{NV STATI / ARTICLES}

The role of occupational gender segregation

Even though there have been considerable advances with regard to women's education and the share of women who are employed, occupational gender segregation is a stable characteristic of the labour market, in Germany and elsewhere (Charles, Grusky 2004). The proportion of women in highly qualified positions remains low in comparison to men (vertical segregation), while at the same time women are often employed in typically female occupations with poorer career prospects (horizontal segregation). Moreover, men often receive higher rewards (in the form of job security, salaries, and training) from their employment than women, independent of the sex composition of their occupation. Compared to other (European) countries, Germany stands out due to its above-average and persistent horizontal gender segregation (Hausmann, Kleinert 2014). Therefore, it is interesting to analyse whether technological change can break up these rigid structures.

One question for ongoing debate is the extent to which new technologies are adopted at varying rates in female- and male-dominated sectors, and whether this is likely to cause changes in women's and men's occupational structure (Voss 2017). Put positively, technological change can open up new opportunities for women and men in the labour market and thus contribute to greater gender equality. Yet these points are currently not at the heart of the discourse (Kutzner, Schnier 2017). More attention is paid to certain adverse effects that may result if opportunities for women in the labour market increase only in the sectors that depend on cheaper, more flexible, and often temporary workers (Piasna, Drahokoupil 2017). An important but less well recognised aspect is the role of training and upskilling in breaking down gender barriers, at least if women and men are given equal access to advanced training (Weusthoff 2017). The study by Seegers (2020) provides a first hint that male and female employees in female-dominated occupations threatened by substitution participate in continuing training almost twice as often as in maledominated occupations.

Turning to possible theoretical explanations for gender differences in men's and women's perceptions of risks in the work context, understanding the mechanisms behind occupational gender segregation seems relevant because these lead to a particular risk context. The gender-segregating structure of the labour market is explained in the literature through various approaches. Many employed women face a double workload, because they are still responsible for much of the unpaid domestic and care work in the private sphere in addition to paid work (Lachance-Grzela, Bouchard 2010). This is the background to the supply-side explanations for why women select typically female occupations to facilitate strategies for combining work and family. Others argue that women follow gender-typical paths because they prefer to work with same-sex colleagues. Yet women's occupational choices should not 
only be seen in the light of their work preferences. From a different angle, structural hurdles and processes of gender discrimination play an important role (Heilman, Caleo 2018). In the sociological and socio-psychological literature, discrimination is attributed to gender-specific categorisation and stereotyping processes (Heilman 2012). One of these stereotypes is the 'gender status belief', which is based on implicit assumptions about men's greater competence and skills. Ridgeway (2001) outlines how the gender status belief produces gender-specific performance expectations by creating a network of constraining expectations and interpersonal interactions. This influences, among other things, the amount of attention paid to men and women, their assertiveness and self-assessment, and the abilities attributed to them. This stereotyping behaviour channels men into the more preferred positions, whereas women are pushed into the more disadvantaged ones (Thébaud 2015). Another concept is self-stereotyping, which describes the way in which individuals integrate stereotypical characterisations of the groups they identify with into their self-concept (Lorenzi-Cioldi 1991). Based on this it is possible for (self-)stereotyping processes to be reproduced.

These general considerations can be sharpened if seen in the context of technological change at work. To this end, the focus now shifts to gender differences in technologyrelated self-perceptions and the question of how these are related to the work environment (Wynn, Correll 2017).

\section{The role of self-perception}

Technology is still understood as an expression of male-dominated culture, in Germany and elsewhere (Kutzner, Schnier 2017). This is evidence in the small proportion of women in the EU with an ICT-related degree or in an ICT-related job (Tarín Quirós et al. 2018). In such a context, the chances are high that women will be faced with stereotypes and the threat of being stereotyped. As a stereotyped group women who are employed in what is typically men's work thus often try not to behave stereotypically so as not to confirm the expectations that they are less capable, less professional, and not available 24/7, which can lead to a poorer performance (e.g. women make a special effort to avoid stereotypes by using technical devices) (Steele 1997). Owing to gender-specific socialisation and self-stereotyping, women tend to rate themselves as less technically competent than men do (Koch, Müller, Sieverding 2008). If women experience a stereotype threat, this may be an additional trigger for them to rate their skills on a lower level. Hence, one might expect that women who experience the implementation of new technologies at work will be more likely to judge their own competence and performance against higher standards than men and will be less sure that they will meet the requirements (Correll 2004). This is likely to give rise to a perceived lack of fit, and this self-feedback might lower 


\section{NV STATI / ARTICLES}

women's aspirations for occupational outcomes (Correll 2001), thus confirming gender stereotypes, whether consciously or not.

Against this backdrop, one can assume that women's technology-related selfperception of their skills is likely to play a major role in male-dominated occupations. Here men are at an advantage: not only do they have higher levels of (self-)attributed competence, they are also more likely than women to have better career prospects and higher rewards (Mihalčová, Pružinský, Gontkovičová 2015). But in femaledominated occupations, too, which are often already characterised by higher degrees of emotional stress, technological transformations may heighten women's concerns if they have a poor self-assessment of their technological skills. As indicated above, the stressors associated with the work-family interface are also negative reinforcing factors for many women. Following these lines of thought, women may be expected to rely on their self-perception when they make judgements about risks and may thus be more aware of certain risks, i.e. the risk of losing one's job, concerns about skill requirements or work performance demands, as well as health-related risks.

Focusing on men, the picture is less clear-cut. Men will often bring with them an initially higher self-assessment of their technological competence (Initiative D21 2018), and a stereotype threat is less likely to arise. Yet this does not mean that men are not likely to anticipate the threats that could result from technological change at work. This is because stereotypes also shape men's way of dealing with work demands, as can be seen, for example, in expectations about full-time availability in conformity with the 'ideal worker' norm, expectations that are connected with constructions of masculinity (Connell 2015). Because masculinity norms are accompanied by high performance demands, men are more likely to anticipate changes in the performance demands that may result from technological change at work. The effort required to meet new performance demands or the feeling of being inadequately prepared to meet these demands act as an additional source of stress. Hence, men may see more risks connected to the psychological aspects of health, whereas risks related to the physical aspects of health will often decrease because of technological change.

Over and above what has already been said, one could also expect only negligible or no gender differences with regard to risk perceptions. One rationale behind this is that technological innovations change everyday lives, and this familiarises both men and women with technology, where some stereotypes will be dismantled. Another rationale is a key finding from job satisfaction research. Despite persistent gender inequalities in the labour market, there is gender gap in job satisfaction in European countries, with women reporting greater job satisfaction than men (Perugini, Vladisavljević 2019). 
The impact of perceived stereotyped judgements and behaviours

For the reasons given above, technological change is likely to result in a more uncertain and threatening work environment, and if these technologies are connoted as masculine, it can be argued that this is likely to increase the chances of gender stereotypes being activated. Stereotypes contain ascriptions of favourable and unfavourable characteristics and have descriptive and prescriptive components (Fiske 1998; Heilman 2001). In the present context, particular attention is paid to gender stereotypes and status beliefs (Ridgeway 1997), and how these interfere with competence expectations, ascribed competencies, and productivity (Foschi 2000). In their theoretical framework of ambivalent sexism, Glick and Fiske (1997) present two types of stereotyped sexism. They distinguish between hostile and benevolent sexism. The former reflects negative attitudes towards one sex based on stereotyping. The latter represents initially positive ascriptions to a gender, which in turn reproduce or reinforce gender stereotypes. Prior literature suggests that women in typically male occupations are often faced with hostile sexism in the form of a harsher observation and evaluation of their productivity by male gatekeepers, and may often feel isolated and excluded. This has been shown to have an impact not only on a range of job outcomes (e.g. on-the-job performance) but also on subjective health and well-being (King, Hebl, George, Matusik 2010). Even if women manage to show high competency and productivity levels, and thus exceed expectations, they may still experience poorer treatment and worse conditions than men (Heilman 2012).

On the basis of this research, it can be argued that technological change will foster discriminatory treatment of women, particularly in typically male work settings. One may therefore assume that women are more likely to perceive technological changes as threatening, particularly with regard to skill requirements and performance demands. Women employed in occupations that are dominated by men are then likely to face a double burden. Being underrepresented and exposed to processes such as (but not limited to) stereotyping and discrimination related to gender and technology, it can be assumed that they evaluate technological change at work as the most threatening.

However, it must be remembered in this discussion that some occupations do not require high-level technological skills, so implicit stereotypes about gender and technology should be less relevant there. It is therefore important to control not only for occupational gender segregation, but also occupational status and the digital intensity of the sector.

In all this, it is also necessary to closely examine other characteristics of workers. One reason for this is that stereotypes and status beliefs are also found in views on other people's migration history (Rosette, Ponce de Leon, Koval, Harrison 2018) or age (Toomey, Rudolph 2017). In the context of this study, older workers can be stereotyped if employers hold the view that older workers tend to be slower to adopt 


\section{NV STATI / ARTICLES}

new technologies and devices at work (Börsch-Supan 2013). Less straightforward, but clearly as important, are the ambivalent stereotypes that exist about people with migration backgrounds in reference to their country of origin (Bradley-Geist, Schmidtke 2018). In the following, age and migration background are therefore used as control variables, since both can influence subjective perceptions of technological change. This study does not, however, interrogate the intersections of gender, migration history, and age and the different privileges and disadvantages attached to these multiple identities (Choo, Ferree 2010).

\section{Open research questions in the analysis of risk perceptions}

As described above, technological change is assumed to have an impact on men's and women's perception of four different types of risks. Since theoretical predictions are ambiguous, the remainder of the article provides a descriptive analysis, comparing men and women across gender-typical and gender-atypical occupations and controlling for various personal, occupational, and structural characteristics in the analysis. The main questions are: To what extent are men and women experiencing changes in the technologies of their workplace? Do men and women anticipate to differing degrees a threat to their future job security and the skills required of them? And do they expect technological changes in their workplace to impact their health or work performance demands?

\section{Data, variables and analytical strategy}

\section{Data}

This analysis uses data from three waves of the Socio-Economic Panel (SOEP.v34), covering the survey years 2015-2017 (Goebel, Grabka, Liebig, Kroh, Richter, Schröder, Schupp 2019). Running since 1984, the SOEP is a multi-dimensional database that contains household- and individual-level data. Using several modes of data collection (with face-to-face interviewing as the default), every year nearly 15,000 households and about 30,000 persons in Germany participate in the SOEP survey. The data cover the past, present, and future situations of respondents (e.g. work situation) using self-reported 'objective and subjective' variables. Items that measure subjectively experienced change in the workplace have only been surveyed in these last waves of the panel. The sample used in the analysis thus includes employed men and women aged 18 to 65 who have participated in at least two panel waves. Self-employed people, trainees, and military personnel are not included. The chosen sample contains 2,740 women and 2,459 men (about $59 \%$ of the sample members were interviewed twice). 


\section{Variables}

The dependent variable of interest is the subjective experience change in the workplace, and not any objective measure of change. Two survey questions are of interest here. Each respondent was asked: 'Sometimes there are changes in the tools and technologies of the workplace - for example, when new technologies, devices, or working or production processes are introduced. What about you? Have there been any changes of this kind in your job in the last year?' (dichotomous dependent variable: $1=$ yes; $0=$ no).

If this condition was met, respondents then estimated the potential risks associated with this over the next two years. A distinction was then made between the risk of losing their job and health risks. Moreover, respondents were asked to state whether they expect their demands for qualifications and work performance to increase or decrease. For this purpose, questions with ordinal response categories are used (ordinal dependent variables: risk/demands will decline, will remain the same, will increase). While the question about technological changes is retrospective (referring to the previous year, i.e. 2015 or 2016), the associated risks are measured prospectively (referring to the subsequent two years). One advantage is that the survey question does not focus solely on automation processes, which are more prevalent in maledominated occupations. A further advantage is that the collection of prospective data will capture chronic risk events that people have to cope with, and not just a snapshot. A disadvantage of the question used in the SOEP is that it covers a range of aspects, some of which do not necessarily capture the effects of technological change.

The following analyses compare men's and women's risk perceptions across gendertypical and atypical occupations. However, information on occupational gender segregation is not included in the SOEP. Year-specific values have therefore been taken from a special evaluation of the Federal Statistical Office using the German Microcensus (Statistisches Bundesamt 2018) and merged with the SOEP applying the 3-digit job classification of the German Federal Employment Agency (Bundesagentur für Arbeit 2011). Three dummy variables are used to categorise the share of women in a given occupation, one for typically male jobs (where the percentage of women in these jobs is from 0 to 30), one for typically female jobs (where the percentage of women is from 70 to 100), and one for integrated jobs (where the percentage of women between 30 and 70) (Busch-Heizmann 2015).

While the goal of the analysis is to show how gender and the share of women in an occupation interact as determinants of perceived changes in the technologies of the workplace, we acknowledge that further variables need to be introduced into the multivariate analysis as controls. To measure the digital intensity of the sector in which women and men are employed (OECD 2019), the analysis differentiates between low intensity of digital transformation (e.g. real estate), medium intensity (e.g. 


\section{NV STATI / ARTICLES}

human health activities), and high intensity (e.g. IT and other information services). The control variables also include age, migration background, willingness to take risks (on a 10 -point scale, ranging between $0=$ not at all willing and $10=$ very willing to take risks, which has been converted so that it ranges between 0 and 1), educational level, occupational status and duties, employment experience, firm size, and sample region. All time-varying variables are measured at two different points in time, 2015 and 2016, and thus refer to the retrospectively measured point in time when a change occurred (or did not occur) in the workplace. Table 1 shows the descriptive values of all variables by gender.

Table 1: Statistics of dependent and independent variables for women and men

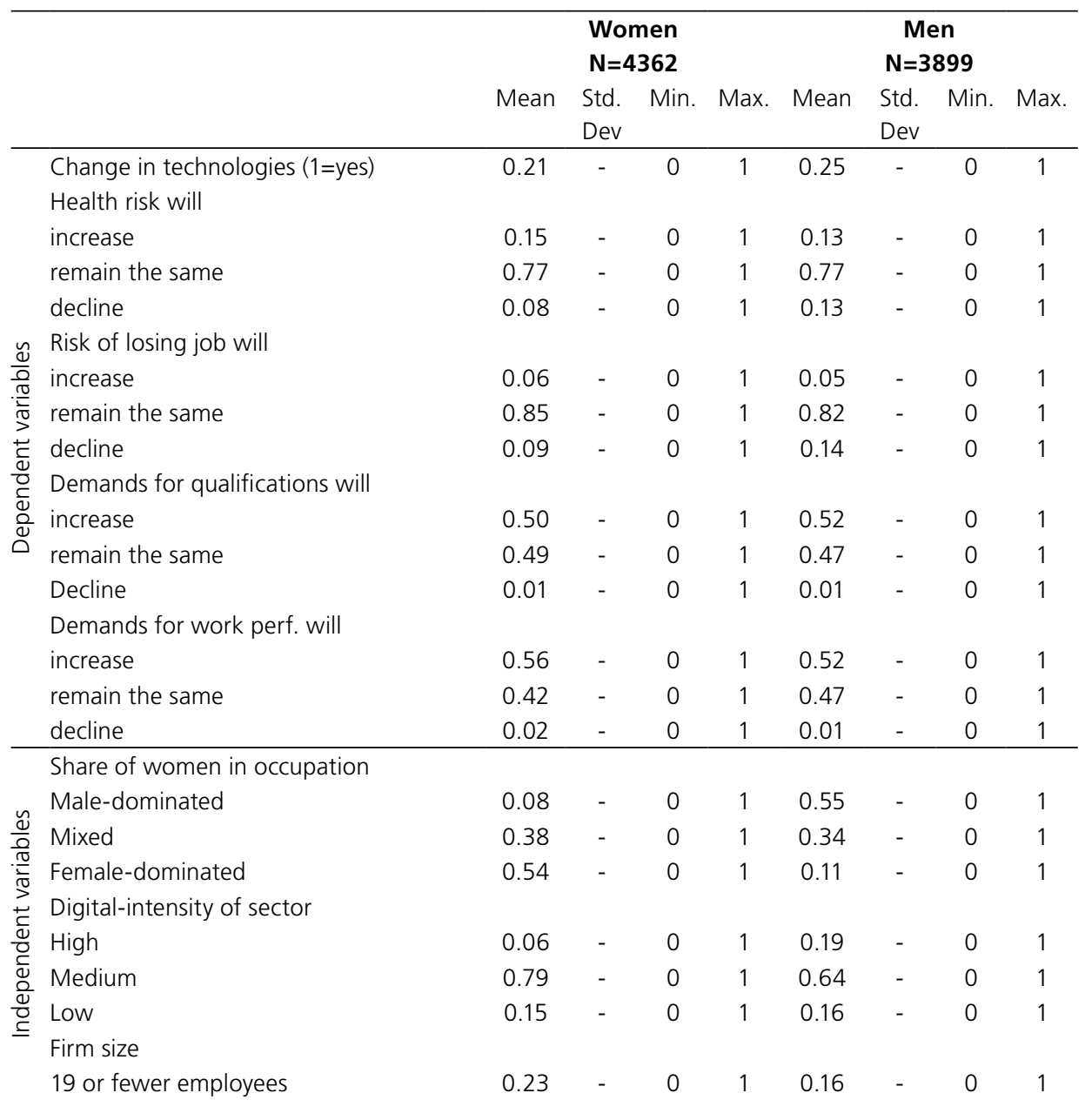




\begin{tabular}{|c|c|c|c|c|c|c|c|c|}
\hline 20 to 199 employees & 0.26 & - & 0 & 1 & 0.26 & - & 0 & 1 \\
\hline 200 to 1999 employees & 0.22 & - & 0 & 1 & 0.24 & - & 0 & 1 \\
\hline 2000 employees or more & 0.29 & - & 0 & 1 & 0.34 & - & 0 & 1 \\
\hline \multicolumn{9}{|l|}{ Educational level } \\
\hline High & 0.39 & - & 0 & 1 & 0.37 & - & 0 & 1 \\
\hline Medium & 0.45 & - & 0 & 1 & 0.36 & - & 0 & 1 \\
\hline Low & 0.17 & - & 0 & 1 & 0.27 & - & 0 & 1 \\
\hline \multicolumn{9}{|l|}{ Occupational status } \\
\hline Worker & 0.11 & - & 0 & 1 & 0.30 & - & 0 & 1 \\
\hline Civil servant & 0.11 & - & 0 & 1 & 0.12 & - & 0 & 1 \\
\hline Employee & 0.78 & - & 0 & 1 & 0.58 & - & 0 & 1 \\
\hline \multicolumn{9}{|l|}{ Occupational duties } \\
\hline Assistant & 0.10 & - & 0 & 1 & 0.04 & - & 0 & 1 \\
\hline Professional & 0.55 & - & 0 & 1 & 0.51 & - & 0 & 1 \\
\hline Specialist & 0.14 & - & 0 & 1 & 0.19 & - & 0 & 1 \\
\hline Expert & 0.20 & - & 0 & 1 & 0.26 & - & 0 & 1 \\
\hline Employment exp. in years & 14.37 & 10.20 & 1 & 48 & 15.94 & 10.50 & 1 & 49 \\
\hline Overtime per week in hours & 1.69 & 2.56 & 0 & 23 & 2.55 & 3.56 & 0 & 23 \\
\hline $\begin{array}{l}\text { Willingness to take risks } \\
\text { ( } 0=\text { not at all, } 1=\text { very willing) }\end{array}$ & 0.45 & 0.21 & 0 & 1 & 0,53 & 0.21 & 0 & 1 \\
\hline Age & 47.53 & 9.14 & 20 & 64 & 46.96 & 9.39 & 20 & 64 \\
\hline \multicolumn{9}{|l|}{ Migration background } \\
\hline No & 0.91 & - & 0 & 1 & 0.90 & - & 0 & 1 \\
\hline Direct & 0.04 & - & 0 & 1 & 0.05 & - & 0 & 1 \\
\hline Indirect & 0.05 & - & 0 & 1 & 0.05 & - & 0 & 1 \\
\hline \multicolumn{9}{|l|}{ Region } \\
\hline Eastern Germany & 0.24 & - & 0 & 1 & 0.22 & - & 0 & 1 \\
\hline Western Germany & 0.76 & - & 0 & 1 & 0.78 & - & 0 & 1 \\
\hline
\end{tabular}

Note: Statistical table of means, standard deviations (for continuous variables only), minimum and maximum of all variables used in the analysis (unweighted). All categorical variables are represented by a set of dummy variables (coded as 1 or 0 ), with one variable for each category. Source: SOEP v.34.

\section{Analytical strategy}

The analysis employs descriptive statistics as well as regressions (Mitchell 2012). For descriptive purposes only, we report unweighted and weighted results (using cross-sectional SOEP-weights that take into account unequal selection probabilities at any stage of sampling as well as unequal response probabilities across waves). To examine the probability of experiencing a change in the tools and technologies of the workplace as the dependent variable, a binary logistic regression is used. Logit and ordinal logistic regressions are carried out in order to identify the determinants of subjective risk perceptions relating to this change. The descriptive results presented 


\section{NV STATI / ARTICLES}

in Table 1 clearly show that regression models for ordinal outcomes should be used in the multivariate analysis of the threat of job loss and threats to health. As for the other two dimensions, only logit models for binary outcomes (demands will increase vs. will remain the same) are suitable, because there are negligible numbers of respondents who expect these demands to decrease.

Since this results in pooled regression models, and it is therefore necessary to take into account the possible correlation of person-specific information, robust standard errors are estimated (Huber 1967; White 1980). The analysis is cross-sectional and cannot disentangle the underlying causal mechanisms. Moreover, it is possible that there are still some unobserved factors that could affect both the experience of changes in the workplace and the related expected outcomes such as health risks.

\section{Results}

\section{Self-reported experience of change in the tools and technologies of the workplace}

As the first step, we examine the self-reported experience of change in the tools and technologies of the workplace. Men are significantly more likely to mention technological changes at work than women (Figure 1). Comparing men and women across gender-typical and gender-atypical occupations, a striking difference is found: $18 \%$ (weighted: $17 \%$ ) of women and $26 \%$ (weighted: $28 \%$ ) of men in femaledominated occupations report changes of this kind in their job. The large difference between these two proportions is significant $(p=0.000)$, suggesting that women in female-dominated occupations are particularly unlikely to experience such changes. Gender differences are also observed within mixed-gender occupations, where $25 \%$ (weighted: $26 \%$ ) of women and $22 \%$ (weighted: $23 \%$ ) of men report the introduction of new technologies. This difference between proportions is smaller but still statistically significant $(p=0.029)$. There is no significant difference between men and women in male-dominated occupations (both $24 \%$ ). 
Figure 1: Self-reported experience of changes in the tools and technologies of the workplace by gender and the share of women in the given occupation

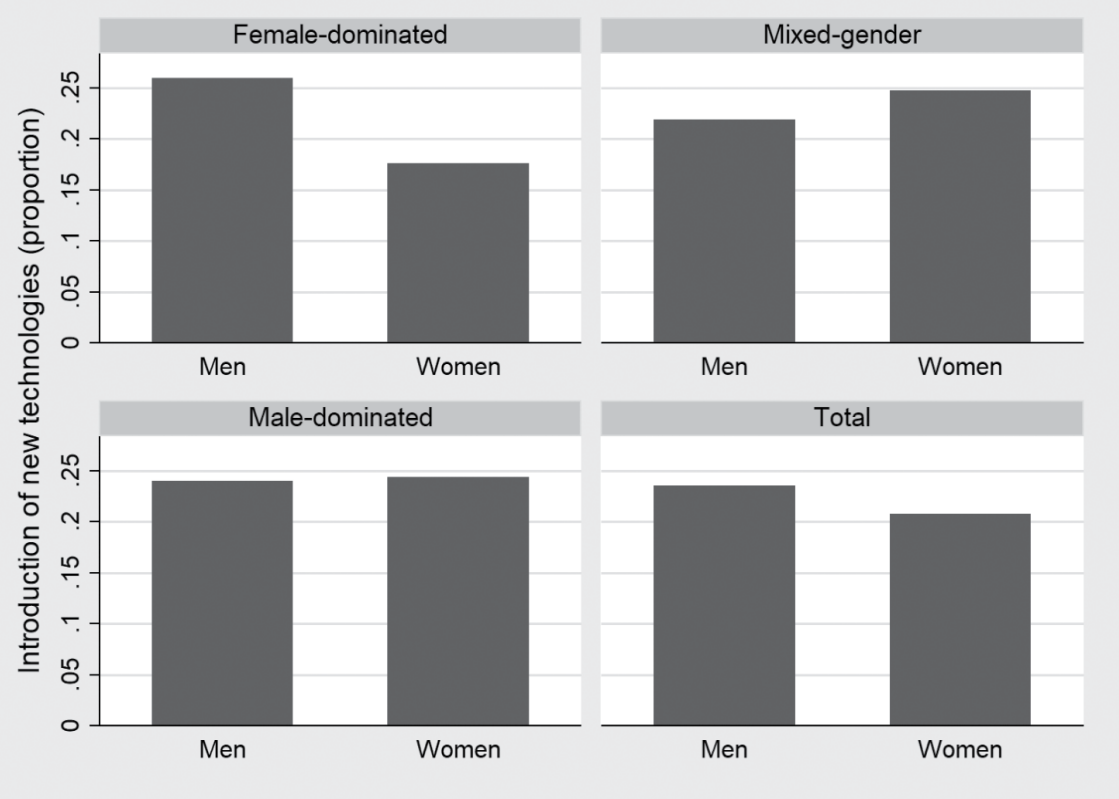

Source: SOEP v.34, unweighted.

It is important to examine whether these gender differences change when companyspecific and occupational characteristics and structural and personal characteristics are taken into account. A logistic regression model is used to focus on the respondents' gender, the share of women in the given occupation, and the interaction between these two categorical variables (all other variables are included as control variables). Overall, the results of this analysis show that the log odds ${ }^{1}$ of experiencing technological innovations are lower for women in female-dominated occupations. By contrast, the log odds are higher for women in mixed-gender occupations. For

1 The logistic regression model quantifies the effect of a variable as a log-odds ratio. Log odds are the logarithmic chance of experiencing a change in technologies at the workplace (estimates available upon request). The estimation results can be displayed in different metrics. The log odds can be exponentiated to give an odds ratio and can also be converted into predicted probabilities. The greater the log odds, the greater the odds (of a change occurring), and the probability increases as the odds increase. To understand the results more easily, one can compare the predicted probabilities for men and women. The predicted probability depends on the level at which the variables in the model are held. For illustrative purposes, one may therefore calculate the average predicted probabilities for men and women across occupations. 


\section{NV STATI / ARTICLES}

a more vivid illustration of these results, Figure 2 presents the predictive margins ${ }^{2}$ of the probability of experiencing technological innovations in relation to the share of women in the given occupation and to gender, averaging across all other values of the covariates in the dataset.

Figure 2: Probability of self-reported change in the tools and technologies of the workplace (predictive margins) by the share of women in the given occupation and gender

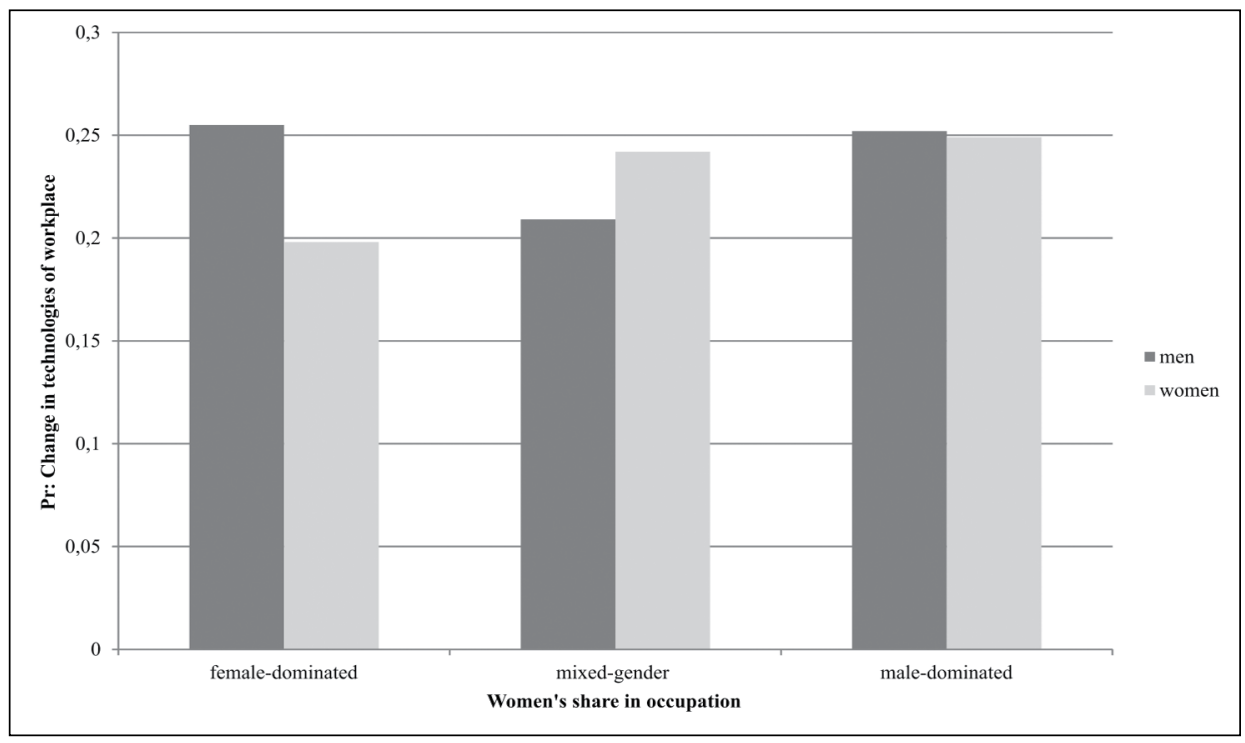

Note: Results from logistic with robust standard errors, controlling for all independent variables listed in Table 1. Source: SOEP v.34, unweighted.

To determine whether the main effects of interest are statistically significant, a three-step framework is used: an omnibus interaction test, a partial interaction test, and a test for interaction contrasts. This analysis reveals that the overall interaction of segregation and gender is significant $(p=0.006)$. When testing the simple effect of gender separately for female-dominated, mixed-gender, and male-dominated occupations, the analysis shows that the gender difference is significant for both female-dominated $(p=0.016)$ and mixed-gender occupations $(p=0.046)$. As already seen in the descriptive analysis, the gender difference is not significant

\footnotetext{
2 The predictive margins are the predicted probabilities that a change occurs for men and women across gender-typical and gender-atypical occupations (keeping everything else constant). It is important to note that this pattern of interaction could vary as a function of the covariates.
} 
for male-dominated occupations $(p=0.937)$. Gender differences are also found across occupations. The interaction between mixed-gender and female-dominated occupations is significant ( $p=0.002$ ). However, this does not hold true for the partial interaction between male-dominated and mixed-gender occupations $(p=0.237)$. The described interactions are significant regardless of whether or not other occupational characteristics (e.g. digital intensity) or personal characteristics (e.g. education or occupational duties) are held constant.

\section{How changes in tools and technologies are expected to affect work}

Figure 3 reveals the extent to which men and women who have experienced technological change at their workplace expect that this will influence their work over the next two years. With regard to health risks and the risk of job loss, some expect an increase, others expect a decrease in risks. A large proportion expect demands for qualifications and work performance to increase, while practically no one expects that a decrease in these demands will occur. Compared to demands for qualifications or work performance, perceived threats to health or job security are small: many men and women do not expect any deterioration or improvement in this regard.

Expected changes at the workplace are more strongly associated with a declining risk of job loss, particularly for men in typically male occupations. Men (3.79\%, weighted: $3.84 \%$ ) and women (3.39\%, weighted: $3.60 \%$ ) in gender-typical occupations often judge the risk of losing one's job as low. The perceived risk of job loss is highest for men (6.42\%, weighted: $5.36 \%$ ) and women (10.23\%, weighted: $24.47 \%)$ in gender-atypical occupations, with a clear gender difference.

Men more often expect health risks to decrease, while women more often expect an increase in health risks. Both men (16.07\%, weighted: $20.41 \%)$ and women (19.32\%, weighted: $23.64 \%)$ in gender-atypical occupations often expect their health risks to increase, again revealing gender differences. This is also the case for men and women in gender-typical occupations, with women being more pessimistic about their health risks (15.09\% vs $8.58 \%$, weighted: $15.44 \%$ vs $10.59 \%)$.

When it comes to demands for workplace performance, gender differences are found in male- and female-dominated occupations, with women more often perceiving increasing demands than men. Women in gender-typical occupations are the most likely to expect an increase in demands for qualifications (55.34 \%, weighted: $56.44 \%)$. In male-dominated occupations, men more often expect an increase in demands for qualifications than women $(51.87 \%$ vs $37.08 \%$, weighted: 49.33 vs $36.17 \%)$. 


\section{NV STATI / ARTICLES}

Figure 3: Perceptions of benefits and threats by the share of women in the given occupation and gender

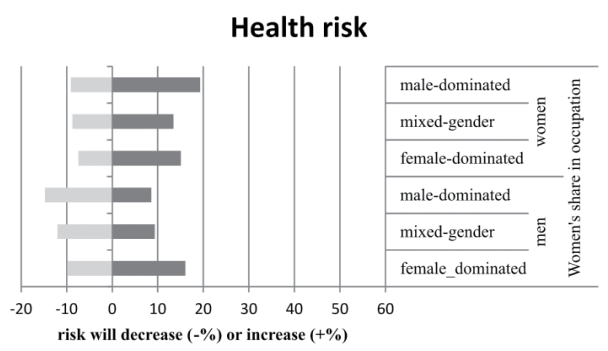

Demands for work performance

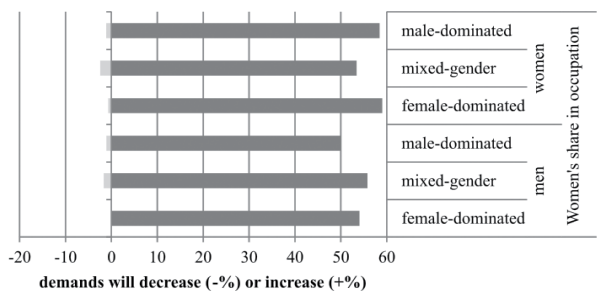

Risk of losing job

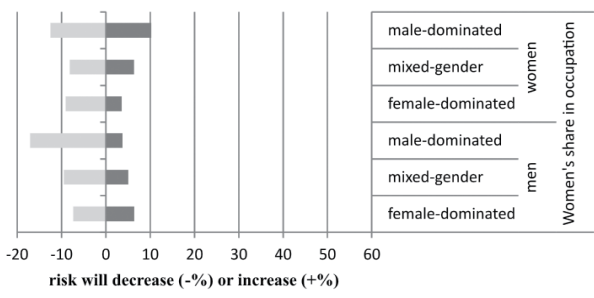

Demands for qualifications

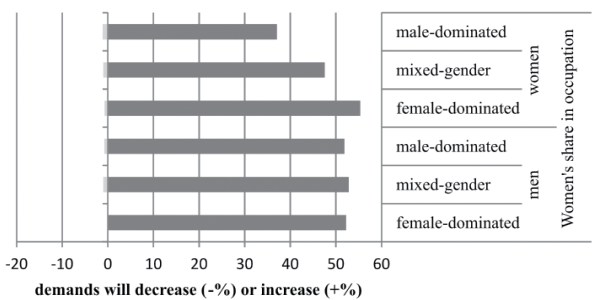

Note: This figure expresses only two proportions for each of the four variables of interest: benefit perceptions (left side of the $y$-axis) and risk perceptions (right side of the $y$-axis). Taking into account the third response category ('remain the same') and converting negative numbers into positive numbers, the results sum up to $100 \%$. Source: SOEP v.34, unweighted.

The remainder of this section reviews selected results from the multivariate models. In this analysis, interactions between gender and the share of women in the given occupation do not have to be taken into account (after formal tests of interaction). The model specification is thus simpler but still controls for all other variables shown in Table 1.

As shown in the left panel of Figure 4, significant gender differences are found for the perception of health risks, as women have a higher probability of risk perception in this area, while the probability of perceiving the benefits of technological change is lower for them. Looking at occupational gender segregation, there are no significant differences when comparing male-dominated and mixed-gender occupations. However, the analysis reveals that on average the probability of perceiving an increase in health risks is higher in female-dominated occupations than male-dominated and mixed-gender occupations. Turning to the perceived risk of losing one's job (right panel of Figure 4), the effects of gender are insignificant. Significant differences are found, however, when the effect of the share of women in the given occupation is 
considered. Those employed in male-dominated occupations are more likely to expect a decrease in the risk of job loss.

Figure 4: Perceptions of health risks and the risk of job loss by the share of women in the given occupation and gender (predictive margins)

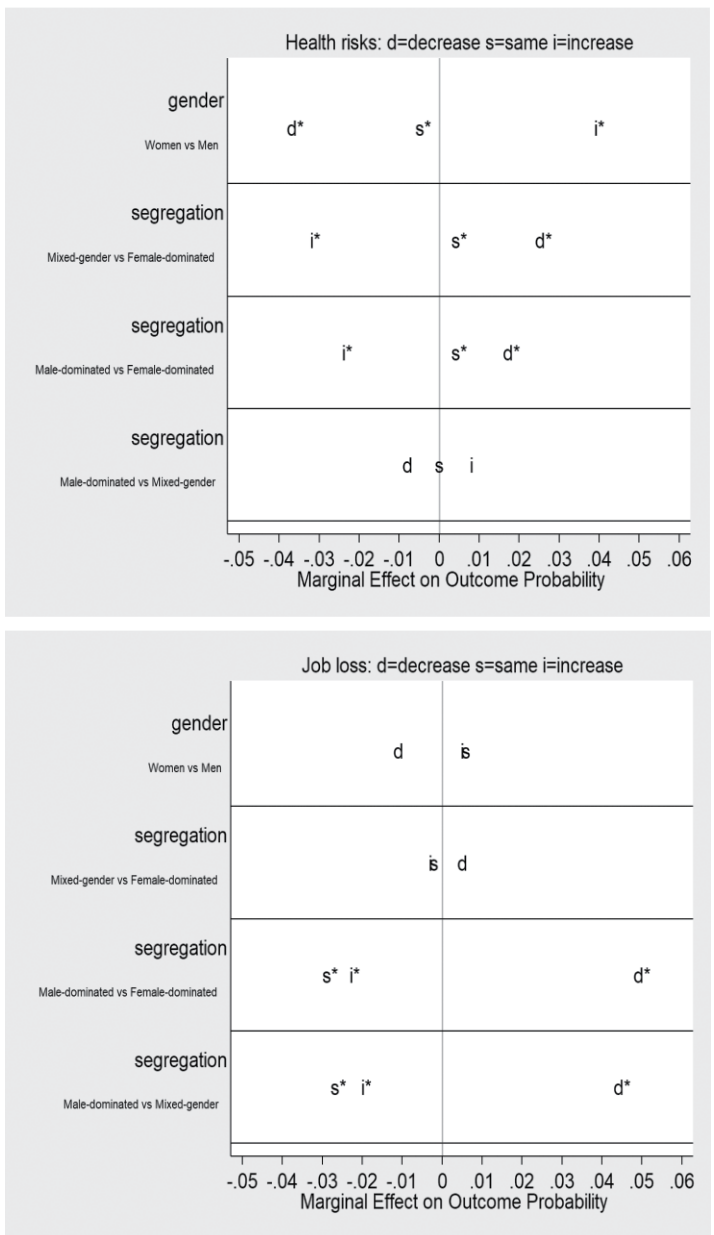

Note: Results from the ordinal logistic regression with robust standard errors, controlling for all independent variables listed in Table 1. ${ }^{*} p<0.05$. Source: SOEP v.34, unweighted.

With regard to a perceived increase in demands for qualifications $(p=0.102)$ and work performance $(p=0.342)$, the effect of gender is not significant (Figure 5). Compared to respondents in female-dominated occupations, those employed in mixed-gender 


\section{NV STATI / ARTICLES}

( $p=0.042$ ) or male-dominated occupations ( $p=0.015)$ are significantly less likely to perceive an increase in demands for qualifications. The same holds true for demands for work performance. At the end of this presentation of the results, it should not go unnoticed that the results for women in male-dominated occupations who have experienced technological change are based on a small number of observations.

Figure 5: Perceptions of increased demands for qualifications and work performance by the share of women in the given occupation and gender (predictive margins)

Increase in demands for work performance

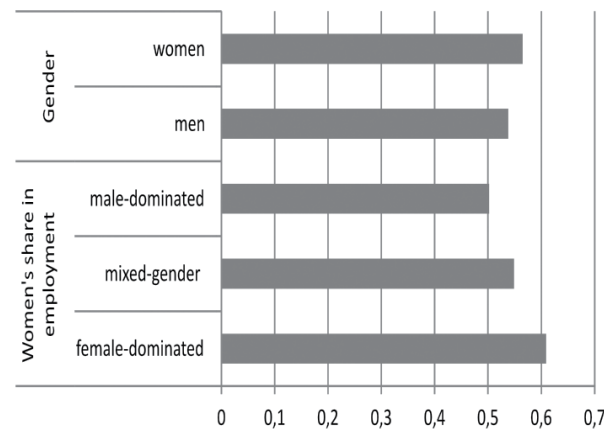

Increase in demands for qualifications

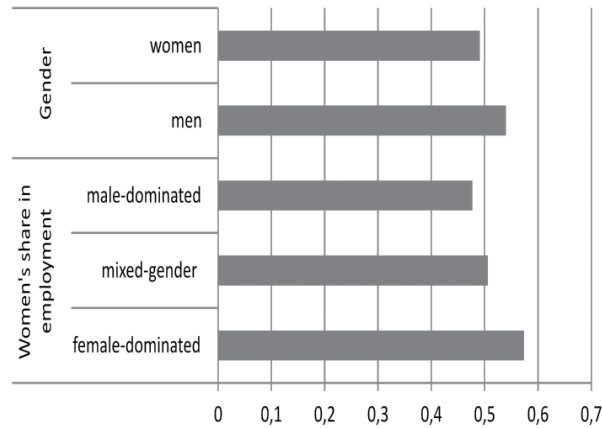

Note: Results from the logistic regression with robust standard errors, controlling for all independent variables listed in Table 1. Source: SOEP v.34, unweighted.

\section{Summary and discussion}

Despite fast-growing research on technological change at work and in general, we know surprisingly little about subjective risk perceptions and possible gender differences. Returning to the initial question about the extent to which men and women are experiencing changes in the technologies of their workplace, this study shows that men and women in female-dominated and mixed-gender occupations are experiencing technological change to varying degrees, even after taking into account other personal, structural, and occupational characteristics. In female-dominated occupations, women are less likely than men to experience changes, but in mixed gender occupations they seem slightly more likely to do so than men. It is important to note that within male-dominated occupations, no gender differences are revealed.

With respect to risk perception, many individuals anticipate no change in demands and risks, and some expect their situation to improve due to technological change, at least with respect to health risks and the risk of job loss. The biggest challenges are seen in demands for qualifications and work performance. This evidence is 
in line with theoretical assumptions about the (perceived) risks of technological change at work, which were presented above. From an employee perspective, the risks of technological change appear to be primarily due to a process of change, acceleration, and compression of work, increasing perceived skill demands and work performance demands.

Technological change is perceived as most threatening in female-dominated occupations, particularly for women. Women more often expect a deterioration in health, but when it comes to the risk of job loss or of increased demands for qualifications and work performance, women do not seem any more worried about the future than men. This may be partly explained by the lower substitution probability of female-dominated occupations. Technological change is accelerating the social transformation into a digital society, with new consequences for the health of employees. In general, the physical burden is decreasing with the support of technical devices, while mental stress is increasing because of the need for simultaneous and faster task completion. In the tertiary sector especially, where mainly women are employed (e.g. the medical and non-medical health sector, public administration, and the retail sector), work pressure seems to increase with the use of technology. Combined with a lower assessment of their own technical skills and the fact that they may face stereotypes and stereotype threats, women's health concerns appear to be well-founded. On top of this, there are generally low-paid jobs with poor working conditions (for example, in care, childcare, and cleaning) that are mainly performed by women. The share of women in an occupation does, however, make a difference. In male-dominated occupations, individuals are more likely to expect a decrease in health risks and in the risk of job loss, irrespective of gender. They are also less likely to expect an increasing demand for qualifications and work performance. Individuals in male-dominated occupations may be more used to technological change, which could reproduce gender status beliefs and reinforce gender-specific self-expectations. Moreover, their jobs are often becoming less physically demanding, and technological change often reduces the exposure to dangerous tasks. Working with technology and changes in tools and technologies are more of a new experience for those working in female-dominated occupations, and this may amplify risk perception, for both men and women. In light of these findings, future research should more closely explore the extent to which men's and women's risk perceptions vary across occupations, hierarchical positions, and sectors. Moreover, to what extent the division of domestic labour, which continues to be carried out mainly by women, plays a role has not been explicitly examined in the empirical models. In connection with the still-predominant male breadwinner model, especially in male-dominated occupations, this seems to have an influence and should be investigated in future analyses. 


\section{NV STATI / ARTICLES}

The results so far give no support to the claim that gender stereotypes and selfcharacterisations, though only implicitly measured, increase women's risk perception to a greater extent than men's. Yet this result is based only on a small number of cases, since few women work in atypical occupations and have experienced a change in the workplace. The risk perceptions that were examined also need to be further refined in future analyses, as health risks may, for example, be due to psychological and physiological factors. Another limitation is that - although many characteristics have already been controlled for - the data used cannot show whether individuals have repeatedly experienced technological changes in the past. It should also be mentioned that some individuals who changed jobs between two panel waves and those who lost their job may have been particularly exposed to technological change but are not part of the estimation sample.

Apart from these critical considerations, this study elucidates why further research on technological change in female-dominated occupations may be particularly fruitful. This article focuses on the perceptions of technological change in Germany at the micro-/employee level. The relationship between worries and subjective risk perceptions requires further investigation, as Sjöberg (1998) has already pointed out. Furthermore, light needs to be shed on the consequences of stereotyping and discrimination processes for the everyday work of women and men. As a next step, future studies should also address gender-specific risk perceptions in other countries to identify similarities and differences between countries. All in all, there is to date too little theoretical and empirical knowledge about the extent to which men and women evaluate technological change at work differently.

\section{References}

Ahlers, E., C. Klenner, Y. Lott, M. Maschke, A. Müller, C. Schildmann, D. Voss, A. Weusthoff (eds.). 2017. Genderaspekte der Digitalisierung der Arbeitswelt: Diskussionspapier für die Kommission 'Arbeit der Zukunft'. Düsseldorf: Hans-Böckler-Stiftung.

Ahlers, E., B. van Berk, M. Maschke, M. Schietinger, C. Schildmann, K. Schulze Buschoff. 2018. Digitalisierung: Dienstleistungsarbeit im Visier. Was bedeutet Digitalisierung für Tätigkeiten im Bereich von Wissensarbeit und Dienstleistungen? Düsseldorf: Hans-Böckler-Stiftung.

Arntz, M., T. Gregory, U. Zierahn. 2016. The Risk of Automation for Jobs in OECD Countries: A Comparative Analysis. OECD Social, Employment and Migration Working Papers 189. Paris: OECD.

Autor, D. H., M. J.Handel. 2013. Putting Tasks to the Test: Human Capital, Job Tasks, and Wages. Journal of Labor Economics 31: 59-96.

Autor, D. H., F. Levy, R. J. Murnane. 2003. The Skill Content of Recent Technological Change: An Empirical Exploration. The Quarterly Journal of Economics 118 (4): 1279-1333. 
Berger, T., C. B. Frey. 2016. Digitalization, Jobs and Convergence in Europe: Strategies for Closing the Skills Gap. Oxford: Oxford Martin School; University of Oxford.

BMAS. 2016. Digitalisierung am Arbeitsplatz: Aktuelle Ergebnisse einer Betriebs- und Beschäftigungsbefragung. Berlin: BMAS.

Börsch-Supan, A. 2013. Myths, Scientific Evidence and Economic Policy in an Aging World. The Journal of the Economics of Ageing 1: 3-15.

Bradley-Geist, J. C., J. M. Schmidtke. 2018. Immigrants in the Workplace: Stereotyping and Discrimination. Pp. 159-175 in Colella, A. J., E. B. King, J. C. Bradley-Geist, J. M. Schmidtke (eds.). The Oxford Handbook of Workplace Discrimination. Oxford: Oxford University Press.

Bundesagentur für Arbeit 2011. Klassifikation der Berufe 2010. Band 1. Systematischer und alphabetischer Teil mit Erläuterungen. Nürnberg: Bundesagentur für Arbeit.

Busch-Heizmann, A. 2015. Frauenberufe, Männerberufe und die 'Drehtür' - Ausmaß und Implikationen für West- und Ostdeutschland. WSI-Mitteilungen 68 (8): 571-582.

Charles, M., D. B. Grusky. 2004. Occupational Ghettos: The Worldwide Segregation of Women and Men. Stanford, CA: Stanford University Press.

Choo, H. Y., M. M. Ferree. 2010. Practicing Intersectionality in Sociological Research: A Critical Analysis of Inclusions, Interactions, and Institutions in the Study of Inequalities. Sociological Theory 28 (2): 129-149.

Connell, R. 2015. Die soziale Organisation von Männlichkeit. Pp. 119-141 in Connell, R. (ed.). Der gemachte Mann. Wiesbaden: Springer VS.

Correll, S. J. 2001. Gender and the Career Choice Process: The Role of Biased Self-Assessments. American Journal of Sociology 106 (6): 1691-1730.

Correll, S. J. 2004. Constraints into Preferences: Gender, Status, and Emerging Career Aspirations. American Sociological Review 69 (1): 93-113.

DGB Index Gute Arbeit. 2016. Der Report 2016: Wie die Beschäftigten die Arbeitsbedingungen in Deutschland beurteilen. Berlin: DGB. Retrieved 17/8/2020 (https://index-gute-arbeit.dgb.de).

DGB Index Gute Arbeit. 2017. Sonderauswertung. Was bedeutet die Digitalisierung der Arbeitswelt für Frauen? Eine Beschäftigtenumfrage. Berlin: DGB. Retrieved 17/8/2020 (https://www.dgb.de/themen/++co++522d9cd0-0278-11e7-b9a4-525400e5a74a).

Fiske, S. T. 1998. Stereotyping, Prejudice, and Discrimination. Pp. 357-411 in Gilbert, D. T., S. T. Fiske, G. Lindzey (eds.). The Handbook of Social Psychology. Boston, MA, New York: Oxford University Press.

Foschi, M. 2000. Double Standards for Competence: Theory and Research. Annual Review of Sociology 26: 21-42.

Glick, P., S. T. Fiske. 1997. Hostile and Benevolent Sexism: Measuring Ambivalent Sexist Attitudes toward Women. Psychology of Women Quarterly 21 (1): 119-135.

Goebel, J., M. M. Grabka, S. Liebig, M. Kroh, D. Richter, C. Schröder, J. Schupp. 2019. The German Socio-Economic Panel (SOEP). Jahrbücher für Nationalökonomie und Statistik 239 (2): 345-360.

Hammermann, A., O. Stettes. 2016. Qualifikationsbedarf und Qualifizierung: Anforderungen im Zeichen der Digitalisierung. IW Policy Paper 3. Cologne: German 


\section{NV STATI / ARTICLES}

Economic Institute (IW). Retrieved 17/8/2020 (https://www.iwkoeln.de/studien/iwpolicy-papers/beitrag/andrea-hammermann-oliver-stettes-qualifikationsbedarf-undqualifizierung-251836.html).

Hardy, W., R. Keister, P. Lewandowski. 2016. Technology or Upskilling? Trends in the Task Composition of Jobs in Central and Eastern Europe. IBS Working Paper Series, Institute of Structural Research, HKUST IEMS Working Paper No. 216-40.

Hauer, G. 2016. Digitalisierung - Selbstläufer Richtung Gleichstellung? Von der Hartnäckigkeit geschlechtstypischer Zuschreibungen, dem Strukturwandel in wichtigen Frauenbranchen und der Chance sozialer Innovation. WISO 39 (4): 171-183. Heilman, M. E. 2001. Description and Prescription: How Gender Stereotypes Prevent Women's Ascent Up the Organizational Ladder. Journal of Social Issues 57 (4): 657-674. Heilman, M. E. 2012. Gender Stereotypes and Workplace Bias. Research in Organizational Behavior 32: 113-135.

Heilman, M. E., Caleo, S. 2018. Combatting Gender Discrimination: A Lack of Fit Framework. Group Processes \& Intergroup Relations 21 (5): 725-744.

Hirsch-Kreinsen, H., P. Ittermann, J. Niehaus (eds.). 2018. Digitalisierung industrieller Arbeit: Die Vision Industrie 4.0 und ihre sozialen Herausforderungen. Baden-Baden: Edition Sigma.

Hirschi, A. 2018. The Fourth Industrial Revolution: Issues and Implications for Career Research and Practice. The Career Development Quarterly 66 (3): 192-204.

Huber, P. J. 1967. The Behavior of Maximum Likelihood Estimates under Nonstandard Conditions. Proceedings of the Fifth Berkeley Symposium on Mathematical Statistics and Probability 1: 221-233.

Initiative D21. 2018. Digital Gender Gap. Lagebild zu Gender(un)gleichheiten in der digitalisierten Welt. Berlin: Initiative D21 e. V. Retrieved 17/8/2020 (https://initiatived21. de/publikationen/digital-gender-gap/).

Kahneman, D., P. Slovic, A. Tversky. 1982. Judgment under Uncertainty: Heuristics and Biases. Cambridge, UK: Cambridge University Press.

King, E. B., M. R. Hebl, J. M. George, S. F. Matusik. 2010. Understanding Tokenism: Antecedents and Consequences of a Psychological Climate of Gender Inequity. Journal of Management 36 (2): 482-510.

Koch, S. C., S. M. Müller, M. Sieverding. 2008. Women and Computers. Effects of Stereotype Threat on Attribution of Failure. Computers \& Education 51 (4): 1795-1803.

Krieger-Boden, C., A. Sorgner. 2018. Labor Market Opportunities for Women in the Digital Age. Economics: The Open-Access, Open-Assessment E-Journal 12 (28): 1-8, http://dx.doi.org/10.5018/economics-ejournal.ja.2018-28.

Kruppe, T., U. Leber. B. Matthes, K. Dengler, H. Dietrich, H. Janitz, S. Janssen, P. Jaschke, O. Jost, Y. Kosyakova, F. Lehmer, T. Lietzmann, C. Osiander, F. Schreyer, H. Seibert, D. Wiethölter, K. Wolf, G. Zika. 2019. Digitalisierung: Herausforderungen für die Aus- und Weiterbildung in Deutschland. IAB-Stellungnahme. Nürnberg: Institut für Arbeitsmarktund Berufsforschung.

Kutzner, E., V. Schnier. 2017. Geschlechterverhältnisse in Digitalisierungsprozessen von Arbeit. Arbeit 26 (1): 137-157. 
Lachance-Grzela, M., G. Bouchard. 2010. Why Do Women Do the Lion's Share of Housework? A Decade of Research. Sex Roles 63 (11-12): 767-780.

Loewenstein, G. F., E. U. Weber, C. K. Hsee, N. Welch. 2001. Risk as Feelings. Psychological Bulletin 127 (2): 267-286.

Lorenzi-Cioldi, F. 1991. Self-stereotyping and Self-enhancement in Gender Groups. European Journal of Social Psychology 21 (5): 403-417.

Lott, Y. 2014. Working Time Flexibility and Autonomy: Facilitating Time Adequacy? A European Perspective, WSI-Diskussionspapier 190. Düsseldorf: Wirtschafts- und Sozialwissenschaftliches Institut.

Mihalčová, B., M. Pružinský, B. Gontkovičová. 2015. The Consequences of Gender Stereotypes in the Work of Managers. Procedia Economics and Finance 23: 1260-1265. Mitchell, M. N. 2012. Interpreting and Visualizing Regression Models Using Stata. College Station: Stata Press.

OECD. 2017. Going Digital: The Future of Work for Women. Paris: OECD.

OECD. 2019. Roadmap: Digital Intensity, a Taxonomy of Sectors. Pp. 86-87 in OECD (ed.). Measuring the Digital Transformation: A Roadmap for the Future. Paris: OECD Publishing.

Oliveira, D. 2017. Gender und Digitalisierung. Wie Technik allein die Geschlechterfrage nicht lösen wird. Working Paper Forschungsförderung der Hans-Böckler-Stiftung 37. Düsseldorf: Hans-Böckler-Stiftung. Retrieved 17/8/2020 (https://www.boeckler.de/pdf/p_ fofoe_WP_037_2017.pdf).

Perugini, C., M. Vladisavljević. 2019. Gender Inequality and the Gender-Job Satisfaction Paradox in Europe. Labour Economics 60: 129-147.

Piasna, A., J. Drahokoupil. 2017. Gender Inequalities in the New World of Work. Transfer: European Review of Labour and Research 23 (3): 313-332.

Ridgeway, C. L. 1997. Interaction and the Conservation of Gender Inequality: Considering Employment. American Sociological Review 62 (2): 218-235.

Ridgeway, C. L. 2001. Gender, Status, and Leadership. Journal of Social issues 57 (4): 637-655.

Rosette, A. S., R. Ponce de Leon, C. Z. Koval, D. A. Harrison. 2018. Intersectionality: Connecting Experiences of Gender with Race at Work. Research in Organizational Behavior 38: 1-22.

Rump, J., S. Eilers. 2017. Arbeit 4.0 - Leben und Arbeiten unter neuen Vorzeichen. Pp. 3-77 in Rump, J., S. Eilers (eds.). Auf dem Weg zur Arbeit 4.0: Innovationen in HR. Berlin: Springer Gabler.

Schulz-Dadaczynski, A., G. Junghanns, A. Lohmann-Haislah. 2019. Extensives und intensiviertes Arbeiten in der digitalisierten Arbeitswelt - Verbreitung, gesundheitliche Risiken und mögliche Gegenstrategien. Pp. 267-283 in Badura, B., A. Ducki, H. Schröder, J. Klose, M. Meyer (eds.). Fehlzeiten-Report 2019. Digitalisierung - gesundes Arbeiten ermöglichen. Berlin, Heidelberg: Springer.

Seegers, M. 2020. Substitutionsrisiko und Weiterbildungsverhalten im digitalen Wandel: Welche geschlechtsspezifischen Unterschiede gibt es?. Berufsbildung in Wissenschaft und Praxis (BWP), 1: 26-29.

Shoss, M. K. 2017. Job Insecurity: An Integrative Review and Agenda for Future Research. 
Journal of Management 43 (6): 1911-1939.

Sjöberg, L. 1998. Worry and Risk Perception. Risk Analysis 18: 85-93.

Slovic, P. 2000. Perception of Risk. Pp. 220-231 in Slovic, P. (ed.). The Perception of Risk.

Sterling, VA: Earthscan.

Slovic, P., B. Fischhoff, S. Lichtenstein. 2000. Facts and Fears: Understanding Perceived Risk.

Pp. 137-153 in Slovic, P. (ed.). The Perception of Risk. Sterling, VA: Earthscan.

Statistisches Bundesamt 2018. Mikrozensus 2017. Qualitätsbericht. Wiesbaden. Retrieved

17/08/2020 (https://www.destatis.de/DE/Methoden/Qualitaet/Qualitaetsberichte/

Bevoelkerung/mikrozensus-2017.pdf?__blob=publicationFile).

Steele, C. M. 1997. A Threat in the Air: How Stereotypes Shape Intellectual Identity and Performance. American Psychologist 52 (6): 613-629.

Tarín Quirós, C., E. Guerra Morales, R. Rivera Pastor, A. Fraile Carmona, M. Sáinz Ibáńez, U. Madinaveitia Herrera. 2018. Women in the Digital Age. Brussels: European Commission.

Thébaud, S. 2015. Status Beliefs and the Spirit of Capitalism: Accounting for Gender Biases in Entrepreneurship and Innovation. Social Forces 94 (1): 61-86.

Toomey, E. C., C. W. Rudolph. 2017. Age Stereotypes in the Workplace. Pp. 89-95

in Pachana, N. A. (ed.). Encyclopedia of Geropsychology. Singapore: Springer.

Voss, D. 2017. Wie verändert sich der Arbeitsmarkt durch die Digitalisierung? Pp. 27-33 in Ahlers, E., C. Klenner, Y. Lott, M. Maschke, A. Müller, C. Schildmann, D. Voss, A. Weusthoff (eds.). Genderaspekte der Digitalisierung der Arbeitswelt: Diskussionspapier für die Kommission 'Arbeit der Zukunft': Hans-Böckler-Stiftung, Düsseldorf.

Wachinger, G., O. Renn, C. Begg, C. Kuhlicke. 2013. The Risk Perception Paradox Implications for Governance and Communication of Natural Hazards. Risk Analysis 33 (6): 1049-1065.

Weusthoff, A. 2017. Wie können Ausbildung und Qualifizierung im Zuge der Digitalisierung die Geschlechtersegregation am Arbeitsmarkt aufbrechen? Pp. 40-44 in Ahlers, E, C. Klenner, Y. Lott, M. Maschke, A. Müller, C. Schildmann, D. Voss, \& A. Weusthoff (eds.). Genderaspekte der Digitalisierung der Arbeitswelt: Diskussionspapier für die Kommission 'Arbeit der Zukunft'. Düsseldorf: Hans-Böckler-Stiftung.

White, H. 1980. A Heteroskedasticity-Consistent Covariance Matrix Estimator and a Direct Test for Heteroskedasticity. Econometrica journal of the Econometric Society 48 (4): 817-838.

Wynn, A. T., S. J. Correll. 2017. Gendered Perceptions of Cultural and Skill Alignment in Technology Companies. Social Sciences 6 (2), https://doi.org/10.3390/socsci6020045.

(c) BY-NC Katrin Golsch, Marco Seegers, 2020.

(c) BY-NC Institute of Sociology of the Czech Academy of Sciences, 2020.

Katrin Golsch is Professor of Quantitative Methods and Social Structure at the Institute of Social Sciences, Osnabrück University. Contact email: katrin.golsch@uni-osnabrueck.de.

Marco Seegers is a sociologist and a member of the Federal Institute for Vocational Education and Training (BIBB), Division Qualifications, Occupational Integration and Employment, in Bonn. Contact email: Marco.Seegers@bibb.de. 